Article

\title{
Powerful Electron-Transfer Screen-Printed Platforms as Biosensing Tools: The Case of Uric Acid Biosensor
}

\author{
Rocco Cancelliere $^{1}$, Alessio Di Tinno ${ }^{1}$, Antonino Cataldo ${ }^{2}\left(\mathbb{D}\right.$, Stefano Bellucci $^{2, *(D)}$ and Laura Micheli ${ }^{1, *(D)}$ \\ 1 Department of Chemical Sciences and Technologies, University of Rome Tor Vergata, Via della Ricerca \\ Scientifica 1, 00133 Roma, Italy; rocco.cancelliere@uniroma2.it (R.C.); alessio.ditinno@uniroma2.it (A.D.T.) \\ 2 INFN-Laboratori Nazionali di Frascati, Via E. Fermi 54, 00044 Frascati, Italy; antonino.cataldo@lnf.infn.it \\ * Correspondence: bellucci@lnf.infn.it (S.B.); laura.micheli@uniroma2.it (L.M.)
}

Citation: Cancelliere, R.; Tinno, A.D.; Cataldo, A.; Bellucci, S.; Micheli, L. Powerful Electron-Transfer Screen-Printed Platforms as Biosensing Tools: The Case of Uric Acid Biosensor. Biosensors 2022, 12, 2. https://doi.org/10.3390/ bios12010002

Received: 10 November 2021 Accepted: 17 December 2021 Published: 21 December 2021

Publisher's Note: MDPI stays neutral with regard to jurisdictional claims in published maps and institutional affiliations.

Copyright: (c) 2021 by the authors. Licensee MDPI, Basel, Switzerland This article is an open access article distributed under the terms and conditions of the Creative Commons Attribution (CC BY) license (https:// creativecommons.org/licenses/by/ $4.0 /)$.

\begin{abstract}
The use of carbon nanomaterials (CNMs) in sensors and biosensor realization is one of the hottest topics today in analytical chemistry. In this work, a comparative in-depth study, exploiting different nanomaterial (MWNT- $\mathrm{CO}_{2} \mathrm{H},-\mathrm{NH}_{2},-\mathrm{OH}$ and GNP) modified screen-printed electrodes (SPEs), is reported. In particular, the sensitivity, the heterogeneous electron transfer constant $\left(\mathrm{k}^{0}\right)$, and the peak-to-peak separation $(\Delta \mathrm{E})$ have been calculated and analyzed. After which, an electrochemical amperometric sensor capable of determining uric acid (UA), based on the nano-modified platforms previously characterized, is presented. The disposable UA biosensor, fabricated modifying working electrode (WE) with Prussian Blue (PB), carbon nanotubes, and uricase enzyme, showed remarkable analytical performances toward UA with high sensitivity $\left(\mathrm{CO}_{2} \mathrm{H} 418 \mu \mathrm{A} \mu \mathrm{M}^{-1} \mathrm{~cm}^{-2}\right.$ and bare SPE-based biosensor, $\left.33 \mu \mathrm{A} \mu \mathrm{M}^{-1} \mathrm{~cm}^{-2}\right)$, low detection limits $\left(\mathrm{CO}_{2} \mathrm{H} 0.5 \mathrm{nM}\right.$ and bare SPE-based biosensors, $280 \mathrm{nM}$ ), and good repeatability $\left(\mathrm{CO}_{2} \mathrm{H}\right.$ and bare SPE-based biosensors, 5\% and 10\%, respectively). Moreover, the reproducibility (RSD\%) of these platforms in tests conducted for UA determination in buffer and urine samples results are equal to $6 \%$ and $15 \%$, respectively. These results demonstrate that the nanoengineered electrode exhibited good selectivity and sensitivity toward UA even in the presence of interfering species, thus paving the way for its application in other bio-fluids such as simple point-of-care (POC) devices.
\end{abstract}

Keywords: nanomaterials; screen-printed electrodes; uric acid; point-of-care device

\section{Introduction}

Critical importance in electroanalytical measurement is given to the magnitude of the electrochemical response and its reproducibility. There are different ways in which this target can be achieved: first, improving the electron transfer conductivity of the transducers; second, reshaping the geometry of the working or reference electrode [1] (avoiding post-printing modification procedure); finally, attempting to alter the surface area of the electrode. Among these, the electronic transfer is the cardinal attribute behind all the different electrochemical sensors. High electronic transfer values ensure satisfactory efficiency and adequate electrochemical performances for all the different electrochemical platforms. In the field of electrochemistry, the parameter that fully describes the aforementioned process is the heterogeneous electron transfer constant $\left(\mathrm{k}^{0}\right)$. This is strictly dependent on the material that makes up the electrode and gives the electrochemist an indication regarding the electron transfer rate between an electroactive species and the electrodic surface. Randles' theory [2] and Marcus' theory [3], respectively, are the most important theories that allow us to completely measure and understand this parameter. In particular, Randles' work, developed in 1947, describes the determination of the heterogeneous electron transfer constant using electrochemical impedance spectroscopy; whereas, Marcus' model, elaborated in 1956, reports the voltammetric determination of the $\mathrm{k}^{0}$. The extensive comprehension of this electrochemical feature, along with the growing demand for super-sensitive and reliable electrochemical sensors, have paved the way, over the 
last decade, for the development and applications of innovative technologies and materials. In this overall scenario, some works dealing with electrochemical sensors based on nanomaterials-modified platforms are frequently reported in the literature [4-6]. However, despite its crucial importance, only a few papers focus on the role of $\mathrm{k}^{0}$. Nanomaterials, objects having at least one nanometric dimension, have been extensively investigated due to their outstanding chemical, mechanical, magnetic, and electrical properties, given by their small-scale sizes. Moreover, the electrochemical field benefits from the enhanced electrochemical performances of these materials (e.g., sensitivity, stability, selectivity) applied in the modification of electrodic platforms.

Among all the viable nanomaterials, carbon-based (CNMs) have widely been used due to high conductivity, chemical stability, wide voltage range, and fast heterogeneous electron transfer properties, inherited by the carbon electrode ancestors and enhanced by the nanoscale effect. Carbon nanotubes and graphene reported significant findings in electrochemical fields [7-10]. Their electrochemical performances are related to their high conductivity due to their particular electronic structures. The extensive literature reflects their importance in the modification of electrodes: they were used to detect inorganic and organic analytes, decreasing the limit of detection [11-14]. In addition, not only do the "classic" sensors take advantage by using nanomaterials, but the biosensors have experimented with a new burst, too. In fact, the realization of the redox reaction driven by enzymes on pristine electrodes is complicated because the active centers of most biomolecules are located in a deeply positioned hydrophobic pocket $[15,16]$. It was demonstrated in [17] that carbon nanotubes enhanced the direct electron transfer capability between enzymes and electrodes; on the other hand, due to its extraordinary electron transport property and high specific surface area, graphene has promoted the electron transfer between electrode substrates and enzymes. Lastly, nanomaterials provide improved electrocatalytic activity and minimize the electrode surface fouling: these two features make their use extremely advantageous in biosensor development [6,17-20].

Most analytical devices were realized by means of screen-printed electrodes (SPEs) [18,21-23]. These platforms, whose proliferation during recent years has been extraordinarily important in bench and in loco analytical measurements, are obtained by printing different inks on various plastic substrates exploiting thick film technology. SPEs are generally made of three different electrodes (working electrode-WE, counter electrode$\mathrm{CE}$ and reference electrode-RE) realized using various inks. The main goal in the analytical field of sensors is to develop sensitive, inexpensive, and user-friendly platforms [24,25], whereby these electrochemical devices are generally modified with various nanomaterials in order to improve their sensitivity, repeatability, and dependability. The main characteristic of a super-sensitive electrochemical platform is a fast electron transfer process, therefore an effective discharge of the analytical probe at the electrode-solution interface. To ascertain this capability, four fundamental parameters are usually studied: $\mathrm{k}_{0}, \Delta \mathrm{E}, \mathrm{E}^{\circ}$, and Ipa and Ipc, respectively [26]. Carbon-based inks, constituting the WE of SPEs, can be easily modified with electrochemical enhancers: carbon nanomaterials, such as carbon nanotubes (CNTs) or graphene, are among the most prominent examples of materials used for post-printing SPEs modification. The component atoms of graphite, graphene, or nanotubes share the same fundamental structural arrangement in which each structure is made up of six carbon atoms that are tightly bound together in the shape of a regular hexagonal lattice [27]. A singular graphene sheet can be wrapped into a zero-dimensional spherical fullerene, rolled into a one-dimensional carbon nanotube, or multiple graphene sheets can be stacked one upon each other into graphene-nanoplatelets (GNPs) [28]. This is well known in the literature as it confers an excellent electrical conductivity when applied in the modification of disposable screen-printed electrodes $[29,30]$. These nano-modified electrodes have been applied in the buildout of an enzymatic biosensor able to monitor and quantify uric acid (UA) in the nanomolar (nM) concentration range. UA is the ultimate catabolite of purine metabolism in humans and higher primates and plays a clinically valuable diagnostic role [31]. The extent of UA acid levels can be related to several diseases 
and conditions: gout, hyperuricemia, Lesch-Nyhan syndrome, hypertension, diabetes, kidney disease, and cardiovascular disease [32-34].

Many analytical methods have been developed for the determination of UA, ranging from simple colorimetric procedures to fluorimetric [35,36] and chemiluminescence (Chemlum.) methods [37,38], to those of flow injection [39] and high-resolution separation, such as capillary electrophoresis (CE) [40,41] or high-performance chromatography (HPLC) [42,43]. Although widespread, these methods usually lack the selectivity required for UA quantification in complex biological matrices: these difficulties are mainly due to the presence of interfering species. To overcome this problem, various kinds of electrochemical sensors and biosensors for UA determination have been implemented and tested as alternative methods to the aforementioned staple analytical techniques. A comparison between the most representative methods is reported in Table 1.

Table 1. Comparison of different UA detection methods.

\begin{tabular}{|c|c|c|c|c|}
\hline \multicolumn{3}{|c|}{ Method } & LOD [nM] & Ref. \\
\hline \multirow{5}{*}{$\begin{array}{l}\text { Biosensors } \\
\text { Detection } \\
\text { Methods }\end{array}$} & \multirow{3}{*}{ Luminescent } & Colorimetric & $20-50$ & {$[35,36]$} \\
\hline & & Fluorescence & 200 & {$[35,36]$} \\
\hline & & Chemlum. & $(1-3) \times 10^{3}$ & {$[37,38]$} \\
\hline & \multirow{2}{*}{\multicolumn{2}{|c|}{$\begin{array}{l}\text { Amperometric } \\
\text { Potentiometric }\end{array}$}} & 5-100 & {$[32,44]$} \\
\hline & & & $(2-5) \times 10^{3}$ & {$[45]$} \\
\hline \multicolumn{3}{|c|}{ High-Performance Liquid Chromatography } & 10-100 & {$[42,43]$} \\
\hline \multicolumn{3}{|c|}{ Capillary Electrophoresis } & $(2-3) \times 10^{3}$ & {$[40,41]$} \\
\hline \multirow{2}{*}{$\begin{array}{l}\text { Electrochemical } \\
\text { Methods }\end{array}$} & \multirow{2}{*}{ Voltammetry } & DPV & 10-100 & {$[46,47]$} \\
\hline & & SWV & $1-100$ & {$[48,49]$} \\
\hline
\end{tabular}

Among all the different proposed methods, the method based on the enzymatic reaction (uricase) shows up as the most robust. In these biosensors, the selective and sensitive recognition of UA is obtained using Uricase, which catalyzes the following reaction (Equation (1)):

$$
\text { uric acid }+\mathrm{O}_{2}+\mathrm{H}_{2} \mathrm{O} \stackrel{\text { Uricase }}{\longrightarrow} \text { allantoin }+\mathrm{CO}_{2}+\mathrm{H}_{2} \mathrm{O}_{2}
$$

The electrochemical oxidation of the produced $\mathrm{H}_{2} \mathrm{O}_{2}$ (Equation (2)) allows the amperometric detection of uric acid [32,50-52].

$$
\mathrm{H}_{2} \mathrm{O}_{2} \rightarrow \mathrm{O}_{2}+2 \mathrm{H}^{+}+2 \mathrm{e}^{-}
$$

However, the employment of conventional electrodes (i.e., $\mathrm{Pt}, \mathrm{Au}$, carbon, etc.) in $\mathrm{H}_{2} \mathrm{O}_{2}$ oxidation can represent a serious problem due to UA oxidation at such positive potentials. The use of mediators, in our case Prussian Blue (PB), can help solve this problem. As demonstrated in our previous work [24], the deposition of PB on WE allows us to determine the concentration of $\mathrm{H}_{2} \mathrm{O}_{2}$ at a fixed potential $(50 \mathrm{mV})$, exceeding the above-described problems.

This paper describes the morphological and electrochemical characterization of bare, nanomaterial-based SPEs obtained using unmodified and functionalized MWNTs and GNPs. Particular attention has been paid to the electron transfer process, constituting the fundamental process of the increased sensitivity of the nano-modified platforms. The aim of this paper is to properly modify the electrodic surface area by means of various carbonaceous nanomaterials, comparing the electrochemical outputs to determine the most convenient ones in terms of sensitivity and repeatability. In order to ascertain these properties, scanning electron microscopy (SEM), Raman spectroscopy, cyclic voltammetry $(\mathrm{CV})$, and square wave voltammetry (SWV) analysis were performed in the presence of potassium hexacyanoferrate (III), obtaining important information about SPEs' analytical 
performances. The electrochemical outputs deriving from nanoengineered electrodes have been compared to the performances of benchmark, bare SPEs. Hence, the purpose of this study was to develop a biosensor incorporating uricase immobilized onto CNMs-based PB-modified SPEs for the quantitative determination of UA, which is directly proportional to the produced $\mathrm{H}_{2} \mathrm{O}_{2}$. Encouraging results in terms of selectivity, sensitivity and reproducibility toward UA have been obtained, thus paving the way to their feasible application in other bio-fluids such as simple point-of-care (POC) devices.

\section{Materials and Methods}

\subsection{Materials and Methods}

All chemicals from commercial sources were of analytical grade. Ethanol, glutaraldehyde solution, potassium chloride, uricase (U0880-250UN), and uric acid were purchased from Sigma-Aldrich (Steinheim, Germany). Potassium ferricyanide was purchased from Fluka Chemie, Sigma-Aldrich (Buchs, Switzerland). Bare MWNTs, MWNT-OH and $-\mathrm{CO}_{2} \mathrm{H}$, functionalized MWNTs were purchased from Heji Inc. (Hong Kong). $-\mathrm{NH}_{2}$ functionalized MWNTs were purchased from (Waltham, MA, USA). GNPs were produced by microcleavage exfoliation of the expanded graphite (provided by Asbury ${ }^{\circledR}$, Wilmore, KY, USA), as reported in previous studies [53]. The buffer solution used is $0.05 \mathrm{M}$ phosphate buffer saline (PBS), $0.1 \mathrm{M} \mathrm{KCl}, \mathrm{pH}=7.4$.

\subsection{Electrodes}

Screen-printed electrodes (SPEs) were produced in-house with a 245 DEK (Highperformance multi-purpose precision screen printer, Weymouth-UK) screen-printing machine. These devices are composed of three electrodes: a working (WE), a counter (CE), and a reference (RE) electrode, respectively. In particular, the WE (apparent geometric area of $0.07 \mathrm{~cm}^{2}$ ) and CE are deposited using a graphite-based ink (Elettrodag 421) from Acheson (Milan, Italy); whereas, the RE is produced using a silver ink (Acheson Elettrodag 4038 SS). The electrochemical cell (WE, CE, RE) is finely defined using an insulating layer (Argon Carbonflex 25.101S).

\subsection{Apparatus}

Cyclic voltammetry (CV), square wave voltammetry (SWV), and chronoamperometric analysis were performed using an Autolab electrochemical system (Eco Chemie, Utrecht, The Netherlands) equipped with PGSTAT-12 and GPES software (Eco Chemie, Utrecht, The Netherlands). Dispersions were realized using Hielscher UP200St-Ultrasonic Transducer. Morphological analyses were performed using a VEGA II scanning electron microscope (Tescan, Czech Republic). Raman spectra were performed using an Invia Raman microscope (Renishaw, UK) endowed with a 532 and $633 \mathrm{~nm}$ laser, a 100 $\times$ objective, and an $1800 \mathrm{~L} / \mathrm{mm}$ grating.

\subsection{Preparation of MWNT or GNP-Modified SPES}

The carbon nanomaterials employed to modify SPEs have been prepared as reported below. Initially, screen-printed electrodes were amperometrically $(1.7 \mathrm{~V}, 180 \mathrm{~s})$ pre-treated using a $0.05 \mathrm{M}$ phosphate buffer $+0.1 \mathrm{M} \mathrm{KCl}, \mathrm{pH} 7$. At this point, once rinsed using distilled water (to remove salt residues), the electrodes were modified using CNMs. The nanomaterials were prepared for dissolving using an ultrasonic transducer $(200 \mathrm{~W}, 26 \mathrm{kHz}$ and $30 \mathrm{~min}), 1 \mathrm{mg}$ of each powder in a 2:1 ethanol-water mixture to a $1 \mathrm{mg} \mathrm{mL}^{-1}$ concentration. In particular, the drop casting procedure ( $6 \mu \mathrm{L}$ of each CNMs dispersions) was employed to modify the WE of our screen-printed platforms. Once dried at room temperature, the modified CNMs were ready to use.

\subsection{Preparation of Uricase-Based Biosensors}

SPEs have been modified with Prussian Blue (PB). The procedure, here applied, was optimized in our previous work [24]. Subsequently, the PB-modified platforms were cast 
using CNMs as detailed in Section 2.4 Uricase immobilization on the WE surface was realized by exploiting the functional groups of the CNMs with the addition of glutaraldehyde $(1 \% \mathrm{v} / \mathrm{v})$. In particular, a $2 \mathrm{mg} \mathrm{mL}^{-1}$ Uricase solution $\left(10 \mathrm{Umg}^{-1}, 0.1 \mathrm{U}\right.$ each electrode) was prepared using $0.015 \mathrm{M}$ PBS $\mathrm{pH}$ 7.4. The biosensors were stored at $4{ }^{\circ} \mathrm{C}$ in a humid chamber.

\subsection{Analytical Parameters Calculation}

From the analysis of ten different blank samples (in the absence of the requested analyte), the standard deviation (SD) of the obtained current values was estimated. Thus, the limit of detection (LOD) was calculated using Equation (3):

$$
\mathrm{LOD}=\frac{3 \cdot \mathrm{SD}_{\text {blank }}}{\mathrm{S}}
$$

where $\mathrm{SD}_{\text {blank }}$ is equal to the standard deviation of the blank samples and $\mathrm{S}$ is the slope of the calibration curve.

The electronic transfer process was studied using the heterogeneous rate constants [54] $\left(\mathrm{k}^{0}\right)$ for the redox process: $\left[\mathrm{Fe}(\mathrm{CN})_{6}\right]^{3-}+1 \mathrm{e}^{-} \rightleftarrows\left[\mathrm{Fe}(\mathrm{CN})_{6}\right]^{4-}$, as described in detail in our previous work [55]. The $\mathrm{k}^{0}$ was calculated using Equation (4):

$$
\mathrm{k}^{0}=\varphi \sqrt{\frac{\mathrm{D}_{0} \pi v \mathrm{nF}}{\mathrm{RT}}\left(\frac{\mathrm{D}_{\mathrm{R}}}{\mathrm{D}_{0}}\right)^{\alpha}}
$$

where $D_{0}$ and $D_{R}$ are the diffusion coefficient for the ferricyanide $\left(D_{0}\right)$ and ferrocyanide $\left(D_{R}\right), v$ is the scan rate $\left(v^{-1}\right), n$ is the number of electrons involved in the process, $\mathrm{F}$ is the Faraday constant $\left(\mathrm{mol}^{-1}\right), \mathrm{T}$ is the temperature $(\mathrm{K}), \mathrm{R}$ is the universal gas constant $\left(\mathrm{JK}^{-1} \mathrm{~mol}^{-1}\right)$, and $\alpha$ the dimensional transfer coefficient [56]. In particular, assuming the ratio of the anodic and cathodic peaks are approximately equal to $1(\mathrm{Ipa} / \mathrm{Ipc}=1)$, a dimensional transfer coefficient equal to 0.5 was chosen.

According to the Nickolson method [54], where there is a correspondence between each $\Delta \mathrm{E}$ and $\varphi$ value, the parameter $\varphi$ can be obtained using Equation (5) [57]:

$$
\varphi=\frac{(-0.6288+0.0021 \cdot \Delta \mathrm{E})}{(1-0.0170 \cdot \Delta \mathrm{E})}
$$

The Randles-Sevcik equations (Equations (6) and (7)) were exploited for the diffusion coefficients and the percentage increase in faradic current estimation, respectively.

$$
\begin{aligned}
& \mathrm{I}_{\mathrm{p}}=(0.4463) \mathrm{nFAC} \sqrt{\frac{\mathrm{nFvD}_{0}}{\mathrm{RT}}} \\
& \mathrm{I} \%=\left(\frac{\mathrm{I}_{\text {modified }}-\mathrm{I}_{\text {bare }}}{\mathrm{I}_{\text {bare }}}\right) \cdot 100
\end{aligned}
$$

in which, $\mathrm{I}_{\text {modified }}$ corresponds to the faradic current value obtained using CNTs-modified SPEs and $\mathrm{I}_{\mathrm{bare}}$ to the faradic current value obtained with bare SPEs.

\section{Results and Discussion}

\subsection{Morphological Characterization of Carbon Nanomaterials (CNMs) Modified-Platforms}

To investigate the surface modification of working electrodes before and after CNMs drop casting, an SEM observation was carried out. A representative micrograph for each platform is reported in Figure 1. Analyzing the surface of unmodified SPE (bare SPE), reported in Figure 1a, graphite particles emerged from the polymer matrix used for printing purposes. The comparison with the surface of CNMs-modified SPEs highlights that the nanostructures retraced the underlying graphite particles and consequently increased the surface area of working electrodes: the nanomaterials are not coated by the polymer matrix of the conductive inks, and this factor helps dramatically to enhance the surface area. The 
WE modification by means of Uricase severely changes the electrodic surface, is shown in Figure 2.
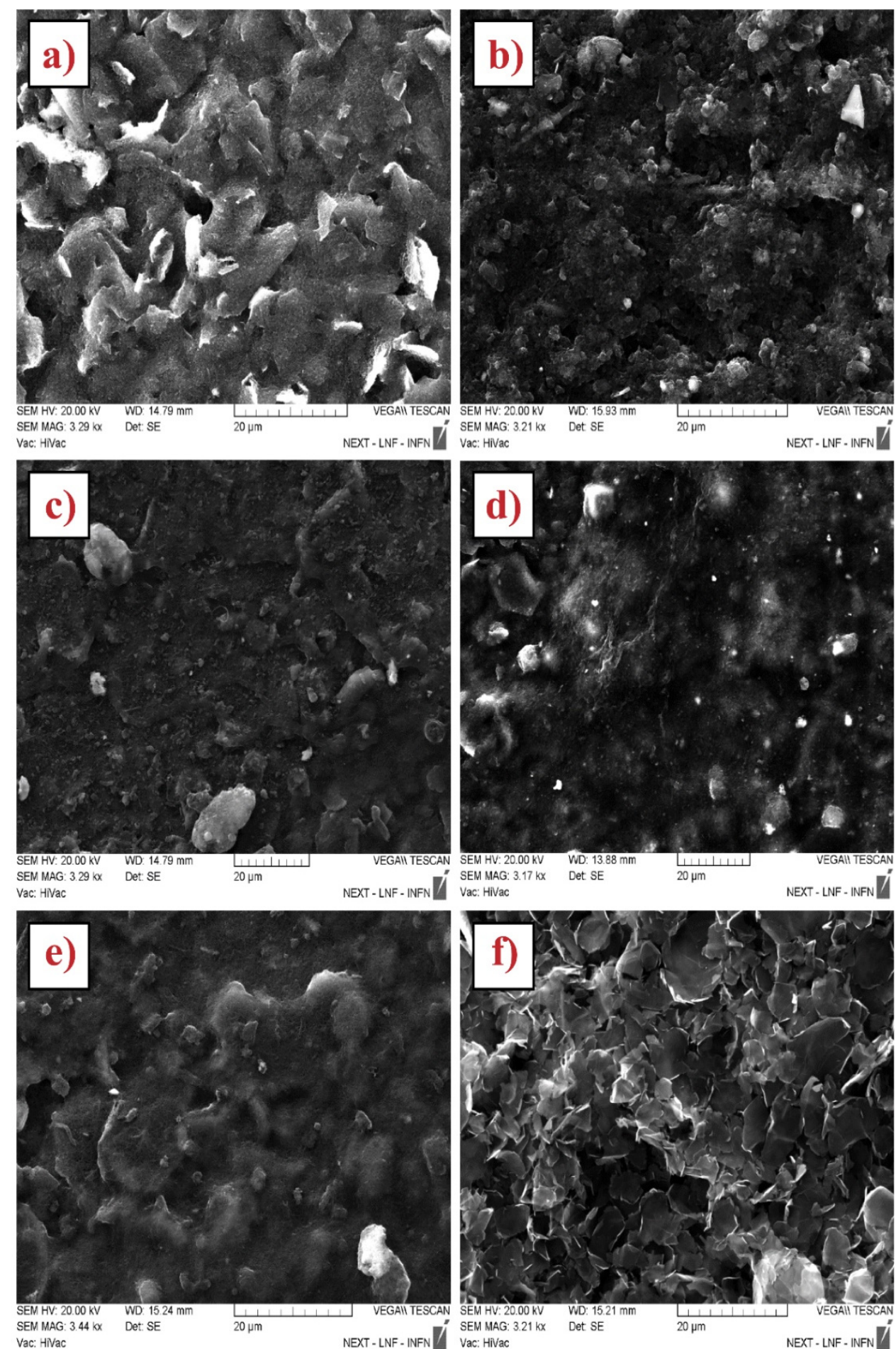

Figure 1. SEM characterization: (a) Bare SPE, (b) Bare MWNT, (c) $\mathrm{CO}_{2} \mathrm{H}-\mathrm{MWNT}-\mathrm{SPE}$, (d) $\mathrm{NH}_{2}$-MWNT-SPE, (e) OH-MWNT, and (f) GNP-modified SPE. 

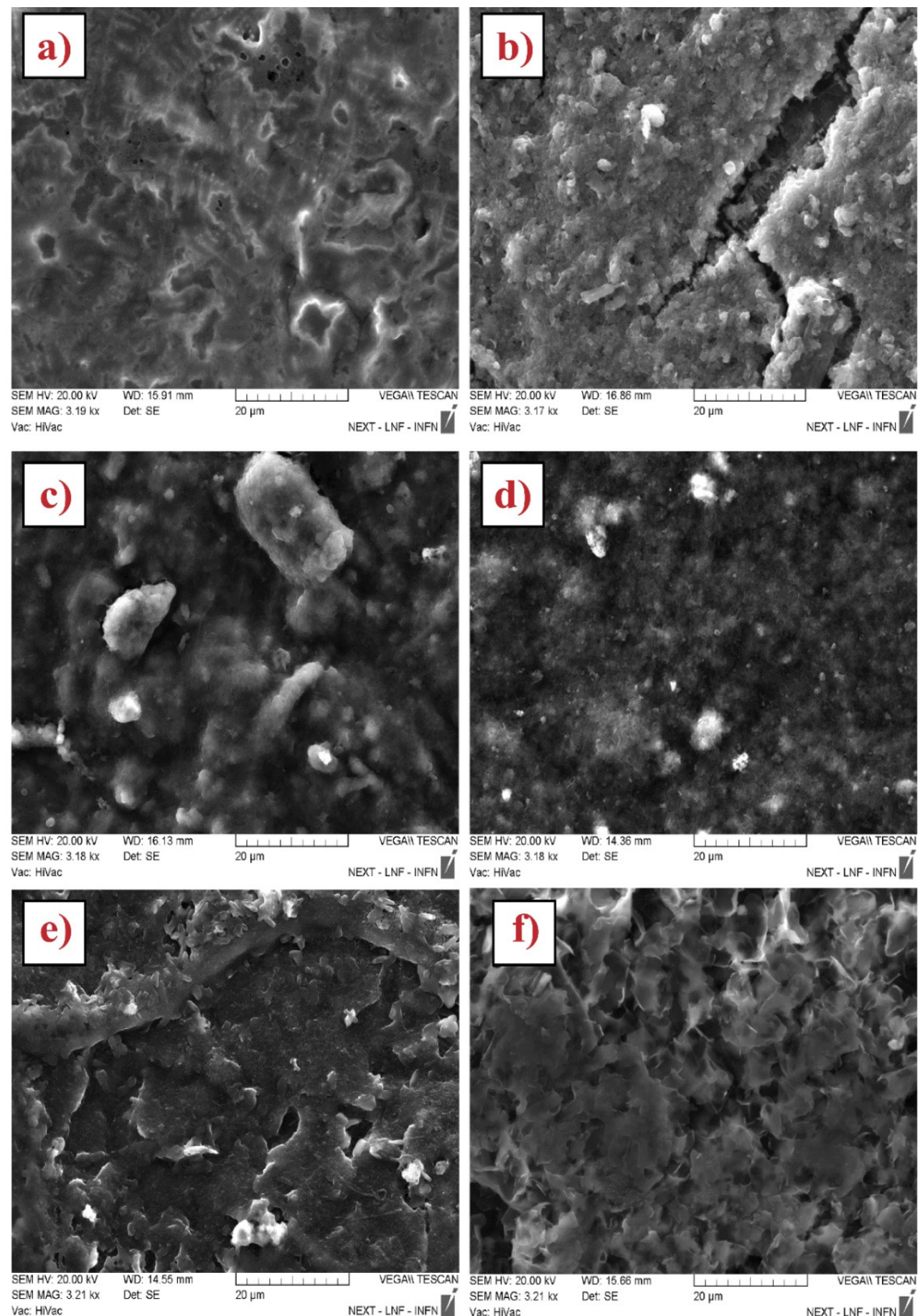

Vac: Hivac Vac: Hivac

NEXT - LNF - INFN

Figure 2. SEM characterization of uricase biosensors based on: (a) Bare SPE, (b) Bare MWNT, (c) $\mathrm{CO}_{2} \mathrm{H}-\mathrm{MWNT}-\mathrm{SPE}$, (d) $\mathrm{NH}_{2}$-MWNT-SPE, (e) OH-MWNT, and (f) GNP-modified SPE.

The uricase adheres homogeneously to the carbonaceous structures: a thin layer of enzyme coats the graphite (bare SPE, Figure 2a) and carbon nanostructure (Figure 2b-f), clearly retracing the underlying structure. The homogeneous and thin coating of the nanostructures is important to ensure a good sensing behavior. In fact, the high surface area obtained by the deposition of nanostructures is now available to detect the electrochemical response selectively by means of an enzyme. The thin enzyme coating guarantees the electrodic area does not decrease. Moreover, the homogeneous coating allows all enzymes to be close to the nanostructure and carry out good selectivity conjugates with high electrochemical properties. 


\subsection{Electrochemical Characterization of CNMs Modified-Platforms}

To ascertain the electrochemical properties that carbon nanomaterials (CNMs) confer to screen-printed electrodes, CV (Figure 3a) and SWV (Figure 3b) analyses were performed using $\left[\mathrm{Fe}(\mathrm{CN})_{6}\right]^{3-/ 4-}$ as an electroactive probe.
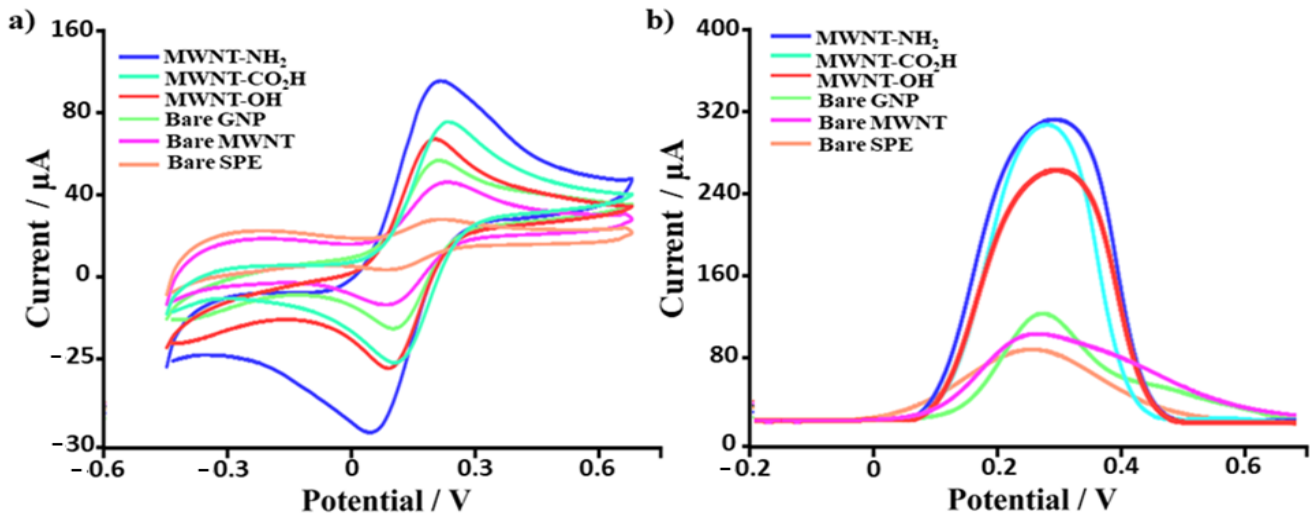

Figure 3. (a) Cyclic and (b) Square Wave voltammogram traces recorded using bare and nanomaterialmodified SPEs (GNP, Bare MWNT, MWNT-OH, MWNT-CO $\mathrm{C}_{2} \mathrm{H}$ and $\mathrm{MWNT}-\mathrm{NH}_{2}$ ) in the presence of $1 \mathrm{mM}$ potassium hexacyanoferrate (III) $+0.1 \mathrm{M} \mathrm{KCl}, \mathrm{pH}$ 7.4. In (a), all traces were recorded at a scan rate of $30 \mathrm{mV} \mathrm{s}^{-1}$; in (b), the amplitude and frequency are equal to $0.05 \mathrm{~V}$ and $5.0 \mathrm{~Hz}$, respectively.

By analyzing the voltammograms reported in Figure 3, it can be readily observed that the presence of nanomaterial-based functionalization produces a dramatic improvement in the magnitude of the voltammetric peak height, reported as the percentage increase $(\%$ increase) of the anodic and cathodic peak current in Table 2 (from 2 to 7 -fold increase in the registered anodic and cathodic peak current). This electrocatalytic response, which formally is a decrease in the overpotential and an increase in the peak current, can be ascribed to the increase of the electrodic surface area originated by nanomaterial modification. Indeed, from the examination of the Randles-Sevcik equation (Equation (6)), one can easily observe that if everything is kept unchanged, with only the electrode area left free to change, the corresponding voltammetric peak height will proportionally increase. This physical post-printing modification is perceived in electrochemical measurements by increasing the voltammetric peak height. This, in turn, allows the measurement of a lower concentration of the target analyte, giving rise to a lower LOD compared to the unmodified SPE (Table 2) and, consequently, an increase in the slope of a plot of peak current against concentration is observed (sensitivity). Reproducibility, peak-to-peak separation (index of ideal behavior of electron transfer process), electron transfer rate constant, and the ratio of the anodic and cathodic peak current intensity were also analyzed. The corresponding results are summarized in Table 2. All the examined analytical parameters confirm the suitability of bare and functionalized CNMs in the electrodic surface area modification, giving rise to a massive improvement in the electrochemical properties of the platforms.

The analysis of the above-reported parameters shows that the best results in terms of $\mathrm{I} \%$ were obtained with aminic $\left(\mathrm{NH}_{2}\right)$ functionalized MWNTs $(7$ and 5 -fold increase for anodic and cathodic peak current, respectively). Whereas the most promising results in terms of repeatability and reproducibility (RSD\%) were obtained for carboxylic $\left(\mathrm{CO}_{2} \mathrm{H}\right)$ functionalized MWNTs (3\%, significantly lower than bare electrodes reproducibility, which is equal to $11 \%$ ). The same nanomaterial-modified SPEs, thus $\mathrm{NH}_{2}$ and $\mathrm{CO}_{2} \mathrm{H}$ functionalized MWNT, present the best results in terms of sensitivity and limit of detection (LOD). These improvements can be ascribed to an increase in the electrodic surface area due to the presence of carbon-based nanomaterials and an enhanced electron transfer rate constants $\left(\mathrm{k}^{0}\right)$. Moreover, unfunctionalized MWNTs (bare) showed the smallest peak-to-peak separation $(\Delta \mathrm{E})$; thus, an ideal reversible electrochemical behavior was observed for these 
nanoengineered platforms. Finally, the GNP-modified platform showed the best result concerning the ratio of the anodic and cathodic peak current intensity.

Table 2. Cathodic and anodic peak current intensity, ratio of the anodic and cathodic peak current intensity, electron transfer rate constant $\left(\mathrm{k}^{0}\right)$, peak-to-peak separation $(\Delta \mathrm{V})$, LOD, sensitivity, reproducibility (RSD\%), and percentage increase estimated for bare and nanomaterial-modified SPEs have been reported. All analytical parameters are obtained from cyclic voltammogram traces.

\begin{tabular}{|c|c|c|c|c|c|c|}
\hline & $\begin{array}{c}\text { Bare } \\
\text { Electrode }\end{array}$ & $\begin{array}{c}\text { Bare } \\
\text { MWNT }\end{array}$ & $\begin{array}{l}-\mathrm{CO}_{2} \mathrm{H} \\
\text { MWNT }\end{array}$ & $\begin{array}{c}-\mathrm{OH} \\
\text { MWNT }\end{array}$ & $\begin{array}{c}-\mathrm{NH}_{2} \\
\text { MWNT }\end{array}$ & Bare GNP \\
\hline \multicolumn{7}{|l|}{$\mathrm{Fe}(\mathrm{CN})_{6}{ }^{4-/ 3-}$} \\
\hline $\mid$ Iap | $[\mu \mathrm{A}]$ & $17 \pm 2$ & $46 \pm 3$ & $93 \pm 3$ & $75 \pm 2$ & $147 \pm 6$ & $64 \pm 4$ \\
\hline$|\mathrm{Icp}|[\mu \mathrm{A}]$ & $10 \pm 1$ & $38 \pm 2$ & $76 \pm 2$ & $62 \pm 3$ & $115 \pm 5$ & $70 \pm 4$ \\
\hline $\mid$ Ipa | / Ipc | & 1.7 & 1.2 & 1.2 & 1.2 & 1.3 & 0.91 \\
\hline$k^{0}[\mathrm{~cm} / \mathrm{s}]$ & / & $3.3 \times 10^{-3}$ & $1.7 \times 10^{-3}$ & $2.2 \times 10^{-3}$ & $5.6 \times 10^{-3}$ & $2.8 \times 10^{-3}$ \\
\hline$\Delta \mathrm{E}[\mathrm{mV}]$ & 380 & 77 & 92 & 85 & 70 & 80 \\
\hline $\mathrm{LOD}[\mu \mathrm{M}]$ & 34.8 & 2.2 & 1.2 & 1.1 & 0.9 & 3.4 \\
\hline $\begin{array}{l}\text { Sensitivity } \\
{\left[\mathrm{mA} / \mathrm{M} \mathrm{cm}^{2}\right]}\end{array}$ & 11.6 & 6.4 & 4.5 & 5.5 & 5.7 & 6.5 \\
\hline $\begin{array}{l}\text { Reproducibility } \\
\text { | Iap | }\end{array}$ & 11 & 6 & 3 & 3 & 4 & 6 \\
\hline $\begin{array}{l}\text { Reproducibility } \\
\text { | Icp | }\end{array}$ & 10 & 5 & 3 & 5 & 4 & 5 \\
\hline $\begin{array}{l}\text { \% Increase } \\
\left|\mathrm{I}_{\mathrm{pa}}\right|\end{array}$ & / & 177 & 460 & 352 & 764 & 276 \\
\hline $\begin{array}{l}\text { \% Increase } \\
\quad\left|\mathrm{I}_{\mathrm{pc}}\right|\end{array}$ & / & 274 & 668 & 516 & 576 & 312 \\
\hline
\end{tabular}

All the reported electrochemical parameters undoubtedly confirm how these welldefined nano-carbonaceous materials possess the required surface structure and electronic properties to support rapid electron transfer, good reproducibility, and sensitivity for electrochemical biosensor implementation.

\subsection{Electrochemical Performances of CNMs-Based Uric Acid Biosensor}

All CNMs-based platforms, once morphologically and electrochemically characterized, were applied as sensing devices for the enzymatic biosensor fabrication. The anodic current recorded in the chronoamperometric traces is due to the oxidation of hydrogen peroxide $\left(\mathrm{H}_{2} \mathrm{O}_{2}\right)$ obtained as a secondary product of the enzymatic conversion of uric acid into allantoin by uricase. The $\mathrm{H}_{2} \mathrm{O}_{2}$ concentration will be proportional to the UA concentration, making possible the amperometric quantification of the target analyte.

The time response and $\mathrm{pH}$ values of electrolytes have a great influence on biosensor activity. Therefore, these two conditions have been carefully optimized. The time is highly suitable for biosensor response. In particular, the current recorded using the bare SPEsbased uricase biosensor at a fixed concentration of UA (1 nM) was plotted against time, and the obtained curve is reported in Figure $4 \mathrm{a}$. The time response selected, where the current values are approximately constant, was 300 s. Once the response time was optimized, the optimization of the uricase-based biosensors was carried out at a continuous uric acid concentration $(1 \mathrm{nM})$ using bare SPEs-based biosensors. Figure $4 \mathrm{~b}$ showed the effect of varied $\mathrm{pH}$ values in a fixed concentration of UA (i.e., $1 \mathrm{nM}$ ). Subsequently, the optimal $\mathrm{pH}$ for the enzymatic reaction was set up by testing values in the $\mathrm{pH}$ range of 6.5-9.5. The recorded current increased when increasing the $\mathrm{pH}$ from 6.5 to 7.5 . When the $\mathrm{pH}$ value was increased further, up to 8.5, the peak current began to decrease. Therefore, $\mathrm{pH} 7.5$ was selected as the best $\mathrm{pH}$ condition. 
a)

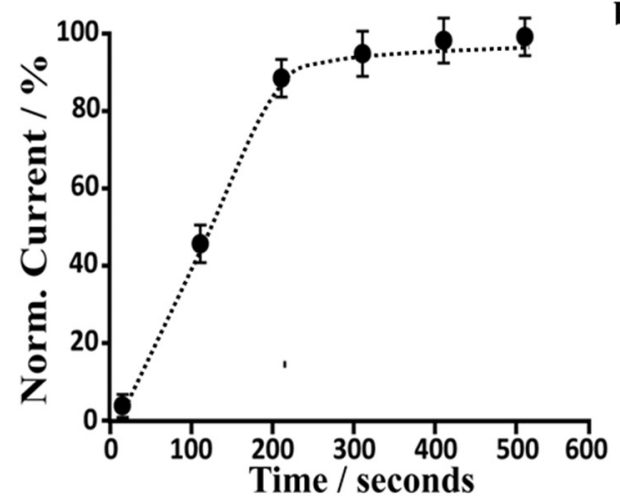

b)

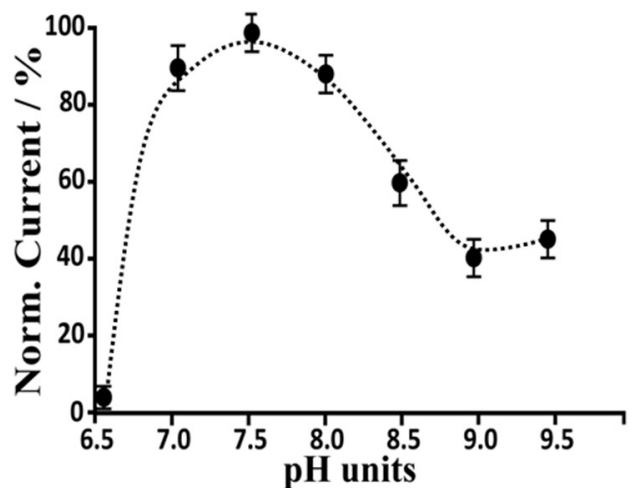

Figure 4. (a) Time response and (b) working $\mathrm{pH}$ values optimization were reported. The results were obtained by analyzing amperometrically bare SPEs in the presence of $1 \mu \mathrm{M}$ UA (in a buffer solution, PBS).

All the nanomaterial-based biosensors were separately tested, and the overall outcomes are summarized in Figure 5 (original traces are reported in Figure S1 in Supplementary Materails). Here, the anodic current values attained by the addition method are reported (Figure 5a). This experiment has been realized, including all the different platforms and the deriving analytical parameters ( $\mathrm{LOD}, \mathrm{K}_{\mathrm{m}}$ and linear range) compared with the uric acid biosensor based on the bare electrode (Table 3). As one can easily notice, the use of nanomaterial-based platforms positively affects the performance of the biosensors (increased anodic current registered), significantly lowering the LOD and extending the linear range. These properties allow us to detect and quantify lower uric acid concentrations (with respect to biosensors based on bare SPE), making the nanoengineered platforms more sensitive and wide-range applicable.

a)

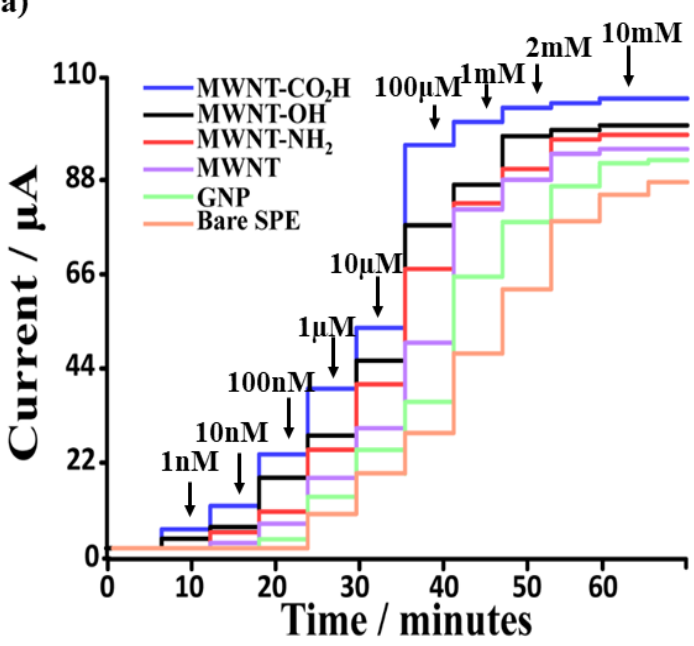

b)

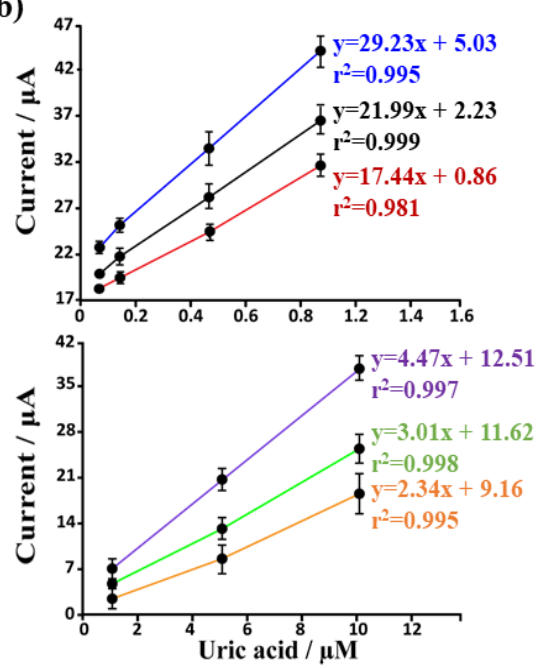

Figure 5. (a) Amperometric traces recorded, using a potential $0.05 \mathrm{~V}$ and the corresponding (b) calibration curves obtained using bare and nanomaterial-modified biosensor (GNP, Bare MWNT, MWNT$\mathrm{OH}, \mathrm{MWNT}-\mathrm{CO}_{2} \mathrm{H}$ and $\mathrm{MWNT}-\mathrm{NH}_{2}$ ) in the presence of an increasing concentration of uric acid (addition method to have a concentration from $0.1 \mathrm{nM}$ to10 $\mathrm{mM}$ ). 
Table 3. LOD, sensitivity, and Km (Michaelis-Menten constant) estimation for bare and CNMsmodified biosensors. These analytical parameters were obtained from chronoamperometric traces (E, time interval and time run respectively equal to $0.05 \mathrm{~V}, 0.01 \mathrm{~s}$, and $300.0 \mathrm{~s}$ ).

\begin{tabular}{ccccccc}
\hline & $\begin{array}{c}\text { Bare } \\
\text { Electrode }\end{array}$ & $\begin{array}{c}\text { Bare } \\
\text { MWNT }\end{array}$ & $\begin{array}{c}-\mathrm{CO}_{2} \mathbf{H} \\
\text { MWNT }\end{array}$ & -OHMWNT & $\begin{array}{c}-\mathbf{N H}_{2} \\
\text { MWNT }\end{array}$ & Bare GNP \\
\hline $\begin{array}{c}\text { LOD } \\
{[\mathrm{nM}]}\end{array}$ & 280 & 74 & 0.5 & 0.9 & 2.1 & 98 \\
\hline $\begin{array}{c}\text { Sensitivity } \\
{\left[\mu \mathrm{A} \mu \mathrm{M}^{-1}\right.} \\
\mathrm{cm}^{-2]}\end{array}$ & 33 & 64 & 418 & 314 & 249 & 43 \\
\hline $\mathrm{K}_{\mathrm{m}}[\mathrm{nM}]$ & 3.0 & 1.8 & 0.04 & 0.07 & 0.08 & 2.1 \\
\hline
\end{tabular}

The current recorded using functionalized MWNT-based biosensors $\left(\mathrm{CO}_{2} \mathrm{H}, \mathrm{OH}, \mathrm{NH}_{2}\right)$ was linear to a UA concentration within the range of $0.1 \mathrm{nM}-1 \mu \mathrm{M}$ for MWNT-modified SPEs. In contrast, a $1 \mathrm{nM}-1 \mathrm{mM}$ linear range was obtained for GNP and bare SPEs-based UA biosensors. The linear regression equation was $\mathrm{y}=\mathrm{a}+\mathrm{bx}$, where $\mathrm{y}$ was the current ( $\mu \mathrm{A}$, sampled at $270 \mathrm{~s})$, and $\mathrm{x}$ was the UA concentration $(\mathrm{nM})$ with the relative $\mathrm{R}$ squared correlated parameter is reported in Figure 5b. According to the calibration curve of current and concentration, the sensitivity and the limit of detection (LOD, calculated using Equation (3)) was reported in Table 3. In particular, the standard deviation $(\sigma)$ necessary for LOD calculation was obtained by analyzing the amperometric currents recorded for blank solution (zero concentration of UA). Finally, the kinetics of the immobilized enzyme (uricase) were calculated (Figure 6), as already shown in our previous works [23,24], using the apparent Michaelis-Menten constant $\left(\mathrm{K}_{\mathrm{m}}\right)$ by the linearization of Lineweaver-Burk expressed by Equation (8):

$$
\frac{1}{\mathrm{I}}=\frac{1}{\mathrm{I}_{\max }}+\frac{\mathrm{k}_{\mathrm{m}}^{\mathrm{app}}}{\mathrm{I}_{\max }[\mathrm{S}]}
$$

where [S], which is the concentration of the substrate, I is the cathodic current recorded applying $0.05 \mathrm{~V}$ potential, $\mathrm{k}_{\mathrm{m}}^{\mathrm{app}}$ is the apparent Michaelis-Menten constant for the enzymatic reaction, and $\mathrm{I}_{\max }$ is the steady-state current. The apparent Michaelis-Menten constant values provide important information regarding the interaction between the enzymatic structure and the target analyte. In particular, the lower the $\mathrm{K}_{\mathrm{m}}$ value, the higher the substrate affinity. Analyzing Table 3, one can notice that functionalized CNMs-based biosensors $\left(-\mathrm{CO}_{2} \mathrm{H},-\mathrm{OH},-\mathrm{NH}_{2}\right)$ show better affinity than the biosensors based on unfunctionalized CNMs (bare MWNTs and bare GNPs) and bar electrodes. This can be ascribed to the presence of functional groups, which not only electrostatically stabilize the enzyme, thus not perturbing the catalytic site and its accessibility to UA, but also improve the electron transfer process at the electrode surface as detailed above.

\subsection{Stability, Reproducibility and Specificity of CNMs-Based Uric Acid Biosensor}

The stability of the CNMs-based biosensors was examined by repeating the measurements of $10 \mu \mathrm{M}$ UA periodically over six weeks. The investigation was realized for all the different platforms stored in a humid chamber at $4{ }^{\circ} \mathrm{C}$ without using any preservatives. The results, reported in Figure 7a, showed an almost constant response for up to fifteen days after their preparation (similar results in terms of registered faradic current). After this period, a significant drop in the electrochemical performances were found, thus indicating a time-dependence of enzymatic activity. Moreover, the biosensor showed an almost identical response (the signal loss is $<5 \%$ ), up to 10 successive measurements with relative standard deviation (RSD) ranging from $5 \%\left(-\mathrm{CO}_{2} \mathrm{H},-\mathrm{OH},-\mathrm{NH}_{2}\right.$, Bare MWNT, GNP) to $16 \%$ (bare SPEs-based biosensors), thus indicating good applicability. 
a)

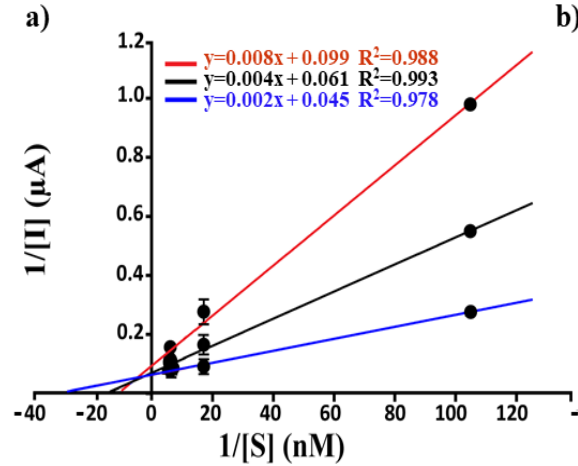

-MWNT-NH ${ }_{2}-$ MWNT-OH - MWNT- $\mathrm{CO}_{2} \mathrm{H}$ b)

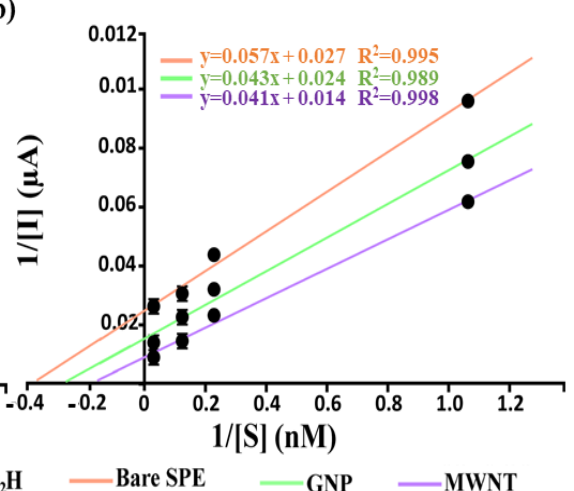

Figure 6. (a) Lineweaver-Burk plots obtained using (a) functionalized $\mathrm{CNMs}$ (MWNT-OH, $-\mathrm{CO}_{2} \mathrm{H}$, and $\mathrm{NH}_{2}$ ) and (b) GNP, Bare MWNT and bare SPE based biosensors in the presence of an increasing concentration of uric acid.

a)

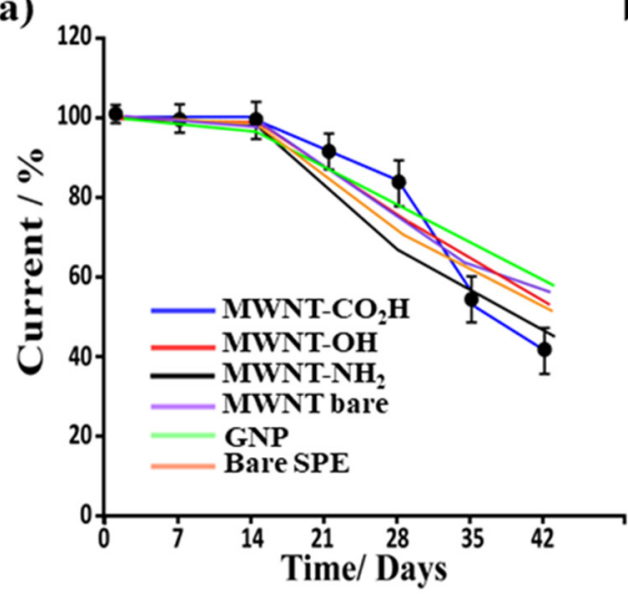

b)

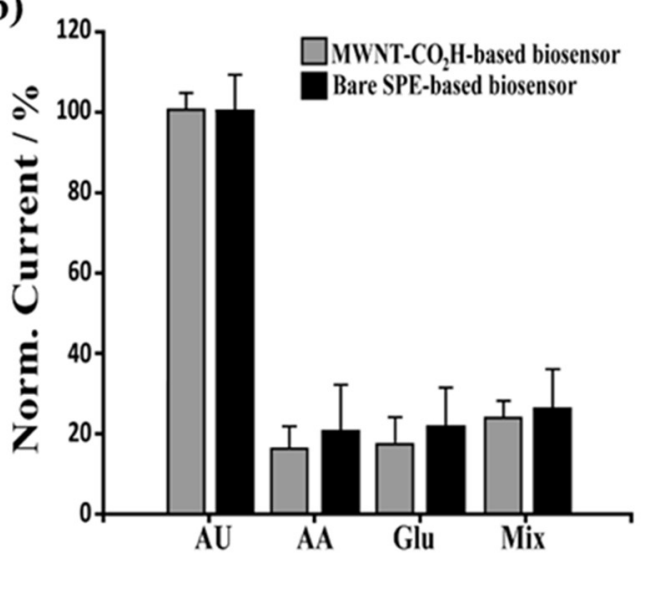

Figure 7. Stability and selectivity of CNMs-based UA biosensors. (a) Stability study. All the biosensors were tested after several days of storage at $4{ }^{\circ} \mathrm{C}$ in a humid chamber, and amperometrically analyzed at the indicated times with $10 \mu \mathrm{M}$ UA concentration. (b) Selectivity study. Effect of the presence of the AA, Glu, and their mix on the biosensor responses obtained for $10 \mu \mathrm{M}$ UA solution.

The repeatability (Table S1 in Supplementary Materails).) and the reproducibility of the biosensors (Table S2 in Supplementary Materails).) was investigated from the response to $10 \mu \mathrm{M}$ UA at three electrodes fabricated by the uniform procedure. The functionalizedbased biosensors $\left(\mathrm{CO}_{2} \mathrm{H}, \mathrm{OH}\right.$, and $\left.\mathrm{NH}_{2}\right)$ showed high reproducibility with an $\mathrm{RSD}$ of 6,4 , and $5 \%$, respectively. Whereas bare MWNT, GNP, and bare electrodes-based UA biosensors showed reproducibility of 10,9 , and $15 \%$, respectively.

The specificity of the biosensor towards UA was investigated by studying some of the interferents commonly found in real samples, such as glucose (Glu) and ascorbic acid (AA). In this study, biosensors based on carboxylic functionalized CNMs have been tested using a fixed concentration $(10 \mu \mathrm{M})$ of $\mathrm{Glu}, \mathrm{AA}$, and a mix of them (1:1 v/v ratio). The results, comparable to those of SPE-based biosensors (Figure $7 \mathrm{~b}$ ), showed that the fabricated biosensor had a strong anti-interference ability.

\subsection{Preliminary Application of CNMs-Based Uric Acid Biosensor in Urine Samples}

To test the ability of the developed biosensors to be used in a real matrix, their application on human urine samples was investigated. Initially, different urine/PB dilutions ratios (untreated, 1:1, 1:10 and 1:100 v/v) were studied. In particular, CV and carboxylic functionalized MWNT-based biosensors were used to verify the presence of any electrochemical interferences correlated to the urine matrix components. From the voltammograms de- 
picted below (Figure 8), it is possible to observe a peak current (between 0.6 and $0.9 \mathrm{~V}$, ascribable to the presence of endogenous UA and AA), which gradually disappears with increasing dilutions. However, the potential presence of electroactive endogenous species and the problems associated with them were easily overcome by diluting the samples (see dilution urine/PBS 1:100 $v / v$ ) and using PB as a diffusion mediator (fixed potential measurements, $0.05 \mathrm{~V}$ ). The standard addition method was used to study the analytical performances of our nanomodifed platforms in spiked urine samples, and the overall outcomes are summarized in Table 4. Moreover, a recovery study using $\mathrm{CO}_{2} \mathrm{H}-\mathrm{MWNT}$ and bare SPE-based biosensors, and analyzing a series of known UA concentrations (0.1, $10,50$ and $100 \mu \mathrm{M})$ (Table 5, estimating \% recovery value), was carried out following the procedure explained by Verma et al. (2019) in their work [58]. In particular, the \% recovery was calculated following Equation (9).

$$
\% \text { Recovery }=\frac{\left(C_{T}-C_{0}\right)}{C_{S}} \times 100
$$

where $C_{T}$ is the total concentration of UA in the spiked urine samples estimated from the calibration plot, $C_{0}$ is the concentration of UA in the unspiked sample $(1.2 \mu \mathrm{M}$ calculated according to the response current with the standard calibration curve), and $C_{S}$ is the concentration of analyte spiked into the sample. The \% recovery values for the spiked samples were 89.0 to $95.3 \%$ and 78.0 to $89.2 \%$ for $\mathrm{CO}_{2} \mathrm{H}-\mathrm{MWNT}$ and bare SPE-based biosensors, respectively. Therefore, a negligible matrix effect and good efficiency of the developed biosensors were verified towards the analysis of AU in clinical detection. Normal excretion of uric acid in urine samples ranges from 250 to 750 milligrams per day (concentration between 250 and $750 \mathrm{mg} / \mathrm{L}$ if one litre of urine is produced per day), an amount easily detectable with our sensor. Moreover, the great sensitivity of this biosensor allows us to significantly dilute complex real matrices (i.e., diabetic and patients undergoing chemotherapy therapies, etc.) to further minimize the interfering effect of other components.

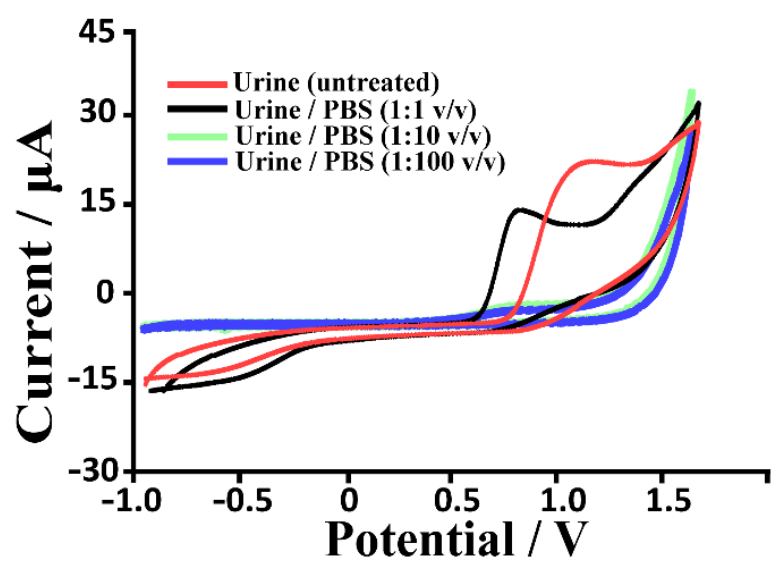

Figure 8. Cyclic voltammograms traces recorded using $\mathrm{MWNT}-\mathrm{CO}_{2} \mathrm{H}$-modified SPEs in diverse urine/PBS dilution ratio (untreated, 1:1, 1:10 and 1:100 $\mathrm{v} / \mathrm{v}$ ). all traces are recorded at a scan rate of $30 \mathrm{mV} \mathrm{s}^{-1}$. 
Table 4. LOD, sensitivity and reproducibility estimated for bare and CNMs-modified biosensor in urine matrix. These analytical parameters are obtained from chronoamperometric traces $(\mathrm{E}$, time interval and time run respectively equal to $0.05 \mathrm{~V}, 0.01 \mathrm{~s}$, and $300.0 \mathrm{~s}$ ).

\begin{tabular}{ccccccc}
\hline & $\begin{array}{c}\text { Bare } \\
\text { Electrode }\end{array}$ & $\begin{array}{c}\text { Bare } \\
\text { MWNT }\end{array}$ & $\begin{array}{c}-\mathrm{CO}_{2} \mathbf{H} \\
\text { MWNT }\end{array}$ & $\begin{array}{c}-\mathrm{OH} \\
\text { MWNT }\end{array}$ & $\begin{array}{c}-\mathbf{N H}_{2} \\
\text { MWNT }\end{array}$ & Bare GNP \\
\hline $\begin{array}{c}\text { LOD } \\
{[\mathrm{nM}]}\end{array}$ & 1400 & 213 & 2.2 & 3.8 & 8.3 & 420 \\
$\begin{array}{c}\text { Sensitivity } \\
{\left[\mu \mathrm{A} \mathrm{mM} \mathrm{mM}^{-1}\right.}\end{array}$ & 13 & 64 & 418 & 314 & 249 & 43 \\
$\left.\mathrm{~cm}^{-2}\right]$ & 17 & 10 & 9 & 9 & 10 & 11 \\
$\mathrm{RSD} \%$ & 17 & & & & & \\
\hline
\end{tabular}

Table 5. Determination of UA concentrations in spiked urine samples.

\begin{tabular}{ccccc}
\hline & $\begin{array}{c}\text { Spiked UA } \\
\text { Concentration } \\
\boldsymbol{C}_{\boldsymbol{S}}(\boldsymbol{\mu M})\end{array}$ & $\begin{array}{c}\text { Recovered UA } \\
\text { Concentration } \\
\left(\boldsymbol{C}-\boldsymbol{C}_{\mathbf{0}}\right)(\boldsymbol{\mu M})\end{array}$ & $\begin{array}{c}\text { Recovery\% } \\
(\mathbf{n}=\mathbf{6})\end{array}$ & RSD\% (n = 6) \\
\hline \multirow{2}{*}{$\mathbf{C O}_{\mathbf{2}} \mathbf{H}$} & 10 & 8.9 & 89.0 & 4 \\
& 50 & 46.8 & 93.6 & 3 \\
Bare SPE & 100 & 95.3 & 95.3 & 3 \\
& 10 & 7.8 & 78.0 & 14 \\
& 50 & 44.4 & 88.9 & 12 \\
\hline
\end{tabular}

\section{Conclusions}

In this paper, an in-depth, electrochemical and morphological characterization of CNMs-modified SPEs has been reported. In particular, $\mathrm{CV}$, allowing us to understand and explain the chemistry related to the different functionalization of the CNMs employed in SPE construction, undertook a quantitative characterization study of electron transfer processes at the diverse CNMs-modified interfaces. Successively, CNMs-SPEs were used for uric acid determination, immobilizing uricase on CNMs-modified platforms using Prussian Blue as an electrochemical mediator. The amperometric response of the uricase-CNMs-PB biosensors was optimized in terms of $\mathrm{pH}$, time analysis, and applied potential, reaching a detection limit of nanomolar level. The results revealed that the prepared biosensor could successfully detect UA at a wide concentration range of $0.1 \mathrm{nM}-100 \mu \mathrm{M}$ with a very low detection limit $\left(\mathrm{CO}_{2} \mathrm{H}\right)$ of $0.5 \mathrm{nM}$, and a lower $\mathrm{k}_{\mathrm{m}}$ value of $0.04 \mu \mathrm{M}$ with respect to bare electrode-based biosensors (LOD $280 \mathrm{nM}$ and $\mathrm{k}_{\mathrm{m}} 4 \mathrm{mM}$ ). At the same time, it exhibited good stability and specificity towards UA in the presence of interferent analytes and good performances in the human urine sample, which confirms its high potential for the efficient detection of UA that can be extended for use in clinical settings.

Supplementary Materials: The following are available online at https: / www.mdpi.com/article/ 10.3390/bios12010002/s1, Figure S1: The original experiment results exploited to create Figure 5a, Table S1: Repeatibility of CNMs-based UA-biosensors response, Table S2: Reproducibility of CNMsbased UA-biosensors response.

Author Contributions: Conceptualization, methodology, investigation, formal analysis, validation, writing-original draft, writing-review and editing, visualization: R.C. Methodology, investigation, formal analysis: A.D.T. Methodology, investigation, formal analysis, writing-original draft. S.B. Resources, investigation A.C., Conceptualization, methodology, validation, resources, writing-original draft, writing-review and editing, supervision: L.M. All authors have read and agreed to the published version of the manuscript.

Funding: This research received no external funding.

Conflicts of Interest: The authors declare no conflict of interest. 


\section{References}

1. Cancelliere, R.; Di Tinno, A.; Di Lellis, A.M.; Tedeschi, Y.; Bellucci, S.; Carbone, K.; Signori, E.; Contini, G.; Micheli, L. An inverse-designed electrochemical platform for analytical applications. Electrochem. Commun. 2020, 121, 106862. [CrossRef]

2. Randviir, E.P. A cross examination of electron transfer rate constants for carbon screen-printed electrodes using Electrochemical Impedance Spectroscopy and cyclic voltammetry. Electrochim. Acta 2018, 286, 179-186. [CrossRef]

3. Marcus, R.A. On the Theory of Oxidation-Reduction Reactions Involving Electron Transfer. II. Applications to Data on the Rates of Isotopic Exchange Reactions. J. Chem. Phys. 1957, 26, 867-871. [CrossRef]

4. Serrano, N.; Castilla, Ò.; Ariño, C.; Diaz-Cruz, M.; Díaz-Cruz, J. Commercial Screen-Printed Electrodes Based on Carbon Nanomaterials for a Fast and Cost-Effective Voltammetric Determination of Paracetamol, Ibuprofen and Caffeine in Water Samples. Sensors 2019, 19, 4039. [CrossRef] [PubMed]

5. Ramnani, P.; Saucedo, N.M.; Mulchandani, A. Carbon nanomaterial-based electrochemical biosensors for label-free sensing of environmental pollutants. Chemosphere 2016, 143, 85-98. [CrossRef] [PubMed]

6. Shao, Y.; Wang, J.; Wu, H.; Liu, J.; Aksay, I.A.; Lin, Y. Graphene Based Electrochemical Sensors and Biosensors: A Review. Electroanalysis 2010, 22, 1027-1036. [CrossRef]

7. Favero, G.; Fusco, G.; Mazzei, F.; Tasca, F.; Antiochia, R. Electrochemical Characterization of Graphene and MWCNT ScreenPrinted Electrodes Modified with AuNPs for Laccase Biosensor Development. Nanomaterials 2015, 5, 1995-2006. [CrossRef] [PubMed]

8. Alabsi, S.S.; Ahmed, A.Y.; Dennis, J.O.; Khir, M.H.M.; Algamili, A.S. A Review of Carbon Nanotubes Field Effect-Based Biosensors. IEEE Access 2020, 8, 69509-69521. [CrossRef]

9. Ehtesabi, H. Carbon nanomaterials for salivary-based biosensors: A review. Mater. Today Chem. 2020, 17, 100342. [CrossRef]

10. Gergeroglu, H.; Yildirim, S.; Ebeoglugil, M.F. Nano-carbons in biosensor applications: An overview of carbon nanotubes (CNTs) and fullerenes (C60). SN Appl. Sci. 2020, 2, 603. [CrossRef]

11. Mo, F.; Xie, J.; Wu, T.; Liu, M.; Zhang, Y.; Yao, S. A sensitive electrochemical sensor for bisphenol A on the basis of the AuPd incorporated carboxylic multi-walled carbon nanotubes. Food Chem. 2019, 292, 253-259. [CrossRef]

12. Li, X.; Ping, J.; Ying, Y. Recent developments in carbon nanomaterial-enabled electrochemical sensors for nitrite detection TrAC Trends Anal. Chem. 2019, 113, 1-12. [CrossRef]

13. Huang, Q.; Lin, X.; Tong, L.; Tong, Q.-X. Graphene Quantum Dots/Multiwalled Carbon Nanotubes Composite-Based Electrochemical Sensor for Detecting Dopamine Release from Living Cells. ACS Sustain. Chem. Eng. 2020, 8, 1644-1650. [CrossRef]

14. Xie, F.; Yang, M.; Jiang, M.; Huang, X.-J.; Liu, W.-Q.; Xie, P.-H. Carbon-based nanomaterials-A promising electrochemical sensor toward persistent toxic substance. TrAC Trends Anal. Chem. 2019, 119, 115624. [CrossRef]

15. Du, X.; Zhang, Z.; Zheng, X.; Zhang, H.; Dong, D.; Zhang, Z.; Liu, M.; Zhou, J. An electrochemical biosensor for the detection of epithelial-mesenchymal transition. Nat. Commun. 2020, 11, 192. [CrossRef] [PubMed]

16. Yoon, H.; Nah, J.; Kim, H.; Ko, S.; Sharifuzzaman, M.; Barman, S.C.; Xuan, X.; Kim, J.; Park, J.Y. A chemically modified laserinduced porous graphene based flexible and ultrasensitive electrochemical biosensor for sweat glucose detection. Sens. Actuators B Chem. 2020, 311, 127866. [CrossRef]

17. Earp, B.; Dunn, D.; Phillips, J.; Agrawal, R.; Ansell, T.; Aceves, P.; De Rosa, I.; Xin, W.; Luhrs, C. Enhancement of electrical conductivity of carbon nanotube sheets through copper addition using reduction expansion synthesis. Mater. Res. Bull. 2020, 131, 110969. [CrossRef]

18. Arduini, F.; Cinti, S.; Scognamiglio, V.; Moscone, D.; Palleschi, G. How cutting-edge technologies impact the design of electrochemical (bio)sensors for environmental analysis: A review. Anal. Chim. Acta 2017, 959, 15-42. [CrossRef]

19. Arduini, F.; Micheli, L.; Moscone, D.; Palleschi, G.; Piermarini, S.; Ricci, F.; Volpe, G. Electrochemical biosensors based on nanomodified screen-printed electrodes: Recent applications in clinical analysis. TrAC Trends Anal. Chem. 2016, 79, 114-126. [CrossRef]

20. Dumitrescu, I.; Unwin, P.R.; Macpherson, J.V. Electrochemistry at carbon nanotubes: Perspective and issues. Chem. Commun. 2009, 41, 6886-6901. [CrossRef] [PubMed]

21. Pumera, M. Electrochemistry of graphene, graphene oxide and other graphenoids: Review. Electrochem. Commun. 2013, 36, 14-18 [CrossRef]

22. Ricci, F.; Amine, A.; Tuta, C.S.; Ciucu, A.A.; Lucarelli, F.; Palleschi, G.; Moscone, D. Prussian Blue and enzyme bulk-modified screen-printed electrodes for hydrogen peroxide and glucose determination with improved storage and operational stability. Anal. Chim. Acta 2003, 485, 111-120. [CrossRef]

23. Cancelliere, R.; Carbone, K.; Pagano, M.; Cacciotti, I.; Micheli, L. Biochar from Brewers' Spent Grain: A Green and Low-Cost Smart Material to Modify Screen-Printed Electrodes. Biosensors 2019, 9, 139. [CrossRef] [PubMed]

24. Cancelliere, R.; Zurlo, F.; Micheli, L.; Melino, S. Vegetable waste scaffolds for 3D-stem cell proliferating systems and low cost biosensors. Talanta 2021, 223, 121671. [CrossRef]

25. Renedo, O.D.; Alonso-Lomillo, M.A.; Martínez, M.J.A. Recent developments in the field of screen-printed electrodes and their related applications. Talanta 2007, 73, 202-219. [CrossRef]

26. Tudorache, M.; Bala, C. Biosensors based on screen-printing technology, and their applications in environmental and food analysis. Anal. Bioanal. Chem. 2007, 388, 565-578. [CrossRef] 
27. Elgrishi, N.; Rountree, K.J.; McCarthy, B.D.; Rountree, E.S.; Eisenhart, T.T.; Dempsey, J.L. A Practical Beginner's Guide to Cyclic Voltammetry. J. Chem. Educ. 2018, 95, 197-206. [CrossRef]

28. Geim, A.K.; Novoselov, K.S. The rise of graphene. In Nanoscience and Technology; Macmillan Publishers Ltd.: Stuttgart, Germany, 2009; pp. 11-19. [CrossRef]

29. Brownson, D.A.C.; Banks, C.E. The Handbook of Graphene Electrochemistry; Springer: London, UK, 2014. [CrossRef]

30. Wang, Y.; Weng, G.J. Electrical Conductivity of Carbon Nanotube- and Graphene-Based Nanocomposites. In Micromechanics and Nanomechanics of Composite Solids; Meguid, S.A., Weng, G.J., Eds.; Springer International Publishing: Cham, Switzerland, 2018; pp. 123-156. [CrossRef]

31. Sher, M.; Faheem, A.; Asghar, W.; Cinti, S. Nano-engineered screen-printed electrodes: A dynamic tool for detection of viruses. TrAC Trends Anal. Chem. 2021, 143, 116374. [CrossRef]

32. Arslan, F. An Amperometric Biosensor for Uric Acid Determination Prepared From Uricase Immobilized in PolyanilinePolypyrrole Film. Sensors 2008, 8, 5492-5500. [CrossRef]

33. Dussossoy, D.; Py, M.L.; Pastor, G.; Boulenc, X. Development of a Two-Site Immunoassay of Recombinant Urate Oxidase (SR 29142) and Its Use for Determination of Pharmacokinetic Parameters in Rats and Baboons. J. Pharm. Sci. 1996, 85, 955-959. [CrossRef] [PubMed]

34. Feig, D.I.; Kang, D.-H.; Johnson, R.J. Uric Acid and Cardiovascular Risk. N. Engl. J. Med. 2008, 359, 1811-1821. [CrossRef]

35. Wang, Y.; Yang, Y.; Liu, W.; Ding, F.; Zhao, Q.; Zou, P.; Wang, X.; Rao, H. Colorimetric and fluorometric determination of uric acid based on the use of nitrogen-doped carbon quantum dots and silver triangular nanoprisms. Microchim. Acta 2018, $185,281$. [CrossRef]

36. Fang, A.; Wu, Q.; Lu, Q.; Chen, H.; Li, H.; Liu, M.; Zhang, Y.; Yao, S. Upconversion ratiometric fluorescence and colorimetric dual-readout assay for uric acid. Biosens. Bioelectron. 2016, 86, 664-670. [CrossRef]

37. Yu, J.; Wang, S.; Ge, L.; Ge, S. A novel chemiluminescence paper microfluidic biosensor based on enzymatic reaction for uric acid determination. Biosens. Bioelectron. 2011, 26, 3284-3289. [CrossRef]

38. Chaudhari, R.D.; Joshi, A.B.; Srivastava, R. Uric acid biosensor based on chemiluminescence detection using a nano-micro hybrid matrix. Sens. Actuators B Chem. 2012, 173, 882-889. [CrossRef]

39. Matos, R.C.; Augelli, M.A.; Lago, C.L.; Angnes, L. Flow injection analysis-amperometric determination of ascorbic and uric acids in urine using arrays of gold microelectrodes modified by electrodeposition of palladium. Anal. Chim. Acta 2000, 404, 151-157. [CrossRef]

40. Tanaka, Y.; Naruishi, N.; Fukuya, H.; Sakata, J.; Saito, K.; Wakida, S. Simultaneous determination of nitrite, nitrate, thiocyanate and uric acid in human saliva by capillary zone electrophoresis and its application to the study of daily variations. J. Chromatogr. A 2004, 1051, 193-197. [CrossRef]

41. Pavlíček, V.; Tůma, P.; Matějčková, J.; Samcová, E. Very fast electrophoretic determination of creatinine and uric acid in human urine using a combination of two capillaries with different internal diameters. Electrophoresis 2014, 35, 956-961. [CrossRef]

42. Cooper, N.; Khosravan, R.; Erdmann, C.; Fiene, J.; Lee, J.W. Quantification of uric acid, xanthine and hypoxanthine in human serum by HPLC for pharmacodynamic studies. J. Chromatogr. B 2006, 837, 1-10. [CrossRef]

43. Dai, X.; Fang, X.; Zhang, C.; Xu, R.; Xu, B. Determination of serum uric acid using high-performance liquid chromatography (HPLC)/isotope dilution mass spectrometry (ID-MS) as a candidate reference method. J. Chromatogr. B 2007, 857, 287-295. [CrossRef]

44. Erden, P.E.; Kılıç, E. A review of enzymatic uric acid biosensors based on amperometric detection. Talanta 2013, 107, 312-323 [CrossRef] [PubMed]

45. Freeman, C.J.; Ullah, B.; Islam, M.S.; Collinson, M.M. Potentiometric Biosensing of Ascorbic Acid, Uric Acid, and Cysteine in Microliter Volumes Using Miniaturized Nanoporous Gold Electrodes. Biosensors 2020, 11, 10. [CrossRef] [PubMed]

46. Liu, X.; Ou, X.; Lu, Q.; Zhang, J.; Chen, S.; Wei, S. Electrochemical sensor based on overoxidized dopamine polymer and 3,4,9,10perylenetetracarboxylic acid for simultaneous determination of ascorbic acid, dopamine, uric acid, xanthine and hypoxanthine. RSC Adv. 2014, 4, 42632-42637. [CrossRef]

47. Yan, Q.; Zhi, N.; Yang, L.; Xu, G.; Feng, Q.; Zhang, Q.; Sun, S. A highly sensitive uric acid electrochemical biosensor based on a nano-cube cuprous oxide/ferrocene/uricase modified glassy carbon electrode. Sci. Rep. 2020, 10, 10607. [CrossRef]

48. Panahi, Z.; Custer, L.; Halpern, J.M. Recent advances in non-enzymatic electrochemical detection of hydrophobic metabolites in biofluids. Sens. Actuators Rep. 2021, 3, 100051. [CrossRef]

49. Income, K.; Ratnarathorn, N.; Khamchaiyo, N.; Srisuvo, C.; Ruckthong, L.; Dungchai, W. Disposable Nonenzymatic Uric Acid and Creatinine Sensors Using $\mu$ PAD Coupled with Screen-Printed Reduced Graphene Oxide-Gold Nanocomposites. Int. J. Anal. Chem. 2019, 2019, 3457247. [CrossRef]

50. Honeychurch, K.; Piano, M. Electrochemical (Bio) Sensors for Environmental and Food Analyses. Biosensors 2018, 8, 57. [CrossRef] [PubMed]

51. Raab, L.S.; Decker, G.L.; Jonas, A.J.; Kaetzel, M.A.; Dedman, J.R. Glucocorticoid regulation of rat liver urate oxidase. J. Cell. Biochem. 1991, 47, 18-30. [CrossRef] [PubMed]

52. Ramanavicius, A. Amperometric biosensor for the determination of creatine. Anal. Bioanal. Chem. 2007, 387, 1899-1906. [CrossRef] 
53. Dabrowska, A.; Bellucci, S.; Cataldo, A.; Micciulla, F.; Huczko, A. Nanocomposites of epoxy resin with graphene nanoplates and exfoliated graphite: Synthesis and electrical properties: Nanocomposites of epoxy resin with GNP and exfoliated graphite. Phys. Status Solidi B. 2014, 251, 2599-2602. [CrossRef]

54. Nicholson, R.S. Theory and Application of Cyclic Voltammetry for Measurement of Electrode Reaction Kinetics. Anal. Chem. 1965, 37, 1351-1355. [CrossRef]

55. Cancelliere, R.; Albano, D.; Brugnoli, B.; Buonasera, K.; Leo, G.; Margonelli, A.; Rea, G. Electrochemical and morphological layer-by-layer characterization of electrode interfaces during a label-free impedimetric immunosensor build-up: The case of ochratoxin A. Appl. Surf. Sci. 2021, 567, 150791. [CrossRef]

56. Konopka, S.J.; McDuffie, B. Diffusion coefficients of ferri- and ferrocyanide ions in aqueous media, using twin-electrode thin-layer electrochemistry. Anal. Chem. 1970, 42, 1741-1746. [CrossRef]

57. Vicentini, F.C.; Ravanini, A.E.; Figueiredo-Filho, L.C.S.; Iniesta, J.; Banks, C.E.; Fatibello-Filho, O. Imparting improvements in electrochemical sensors: Evaluation of different carbon blacks that give rise to significant improvement in the performance of electroanalytical sensing platforms. Electrochim. Acta 2015, 157, 125-133. [CrossRef]

58. Verma, S.; Choudhary, J.; Singh, K.P.; Chandra, P.; Singh, S.P. Uricase grafted nanoconducting matrix based electrochemical biosensor for ultrafast uric acid detection in human serum samples. Int. J. Biol. Macromol. 2019, 130, 333-341. [CrossRef] 